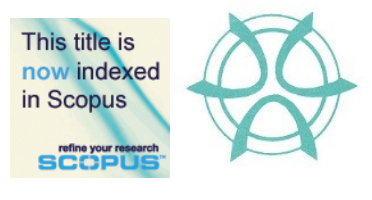

\title{
SURVEILLANCE AND GUARDIANSHIP ATTITUDES: ROLE OF MULTIPLE MEDIATORS
}

\author{
Massoomeh Hedayati Marzbali ${ }^{1}$, Aldrin Abdullah ${ }^{2}$, Mohammad Javad \\ Maghsoodi Tilaki ${ }^{3}$ \\ ${ }^{1,2}$ School of Housing, Building and Planning \\ ${ }^{3}$ School of Humanities \\ UNIVERSITI SAINS MALAYSIA
}

\begin{abstract}
Urban design researchers and environmental criminologists believe that personal and situational characteristics influence how and when residents act as guardians over where they live. However, little is known about the individual factors that explain residential guardianship behaviours. This study focuses on sociophysical factors in explaining residents' willingness to act as guardians to control criminal behaviour through multiple mediators. A sample of 247 residents in Penang, Malaysia was analysed via structural equation modelling. Results demonstrated that although no significant direct association exists between natural surveillance and guardianship, this relationship was mediated via territorial identity and increases in social cohesion. Findings also indicated the significant role of territorial identity, perceived risk and social cohesion in explaining the amount of guardianship attitude. Furthermore, surveillance helps reduce perceived risk among residents. Social cohesion is the most influential factor in shaping the opportunity for capable guardianship in the study area. It is concluded that organising community-based activities will help strengthen community ties, thereby creating substantial willingness among residents to intervene for the common good and building safer communities. Using extensive survey data from a multi-ethnic community in Malaysia, this study brings to the fore the ways in which the sociophysical factors help foster guardianship attitudes within residential contexts using multiple mediators.
\end{abstract}

Keywords: Guardianship attitude, multiple mediators, perceived risk, social cohesion, surveillance

\footnotetext{
1 Senior Lecturer at University Sains Malaysia. Email: hedayati@usm.my
} 
PLANNING MALAYSIA

Journal of the Malaysia Institute of Planners (2020)

\section{INTRODUCTION}

A focal point of recent research on criminology is to understand how crime evolves and the means to curb it, as safety and security are components of sustainability. A wide range of variables are influential in understanding crime. These variables may include, but are not limited to, socioeconomic status (Shaw $\&$ McKay, 1942), areas with a high level of physical disorder (Moley, 2008), absence of stability and social networks (Comstocka et al., 2010), as well as physical design, ranging from neighbourhood-level factors to micro-level features of individual properties, such as the orientation of neighbouring properties and the height of boundary fencing (Armitage \& Joyce, 2017; Marzbali et al., 2012; Sohn, 2016). Felson stated that "crime seeks times and places that are largely unsupervised" (Felson, 2006, p. 79). That one of the key factors that discourages offenders from committing crime in residential settings is the risk of being seen has been well established within criminology research (MacDonald \& Gifford, 1989). This claim has been supported by several studies in which high levels of supervision and natural surveillance opportunities within the neighbourhood environment are associated with low levels of crime (Hollis-Peel \& Welsh, 2014; Reynald, 2011).

The concept of guardianship is central to routine activities approach, which posits that opportunities for crime arise when potential offenders and suitable targets converge in the absence of capable guardians. On the basis of Cohen and Felson's model, capable guardians can serve as key actors in the crime event model (Cohen \& Felson, 1979). However, the extent to which residents carry out supervision in their neighbourhood and which factors regulate the amount of supervisions and interventions are largely unknown (Reynald \& Moir, 2018).

Evidence of opportunities for and motivations behind guardianship is limited (Moir et al., 2018), thereby warranting additional research. An interview study suggests that physical design, sense of responsibility, perceptions of crime and relationships with neighbours facilitate residential monitoring (Reynald, 2010). Only a few studies focused on measuring opportunities for natural surveillance that are generated by the physical environment as an indicator of supervision (for example, Wilcox et al., (2007)). Reynald (2011) is one of the few studies to date that explicitly identify both spatio-physical and social factors that influence monitoring and intervention in residential areas in the Netherlands. In a similar vein, Reynald and Elffers (2009) integrated defensible space and routine activities theories. However, they neglected the mediational effects in their proposed model, which will be addressed by this study. Rather than the direct relationship, the current study proposes a model to examine which variables clarify the nature of the relationship between surveillance and guardianship attitudes. To date, no such study has been conducted in a Malaysian context. To fill this gap, the current study was undertaken to investigate the role that physical design and social environment play in facilitating intervention among potential residential guardians through multiple mediation effects in a multi-ethnic society. 
Massoomeh Hedayati Marzbali, Aldrin Abdullah \& Mohammad Javad Maghsoodi Tilaki

Surveillability and Guardianship Attitudes: The Role of Multiple Mediators

The model in this study tests the link between surveillance and guardianship attitudes and expands the defensible space concept, routine activities approach and social disorganisation model in two ways. Firstly, drawing on an environmental psychology perspective, we argue that aside from social cohesion, perceived risk can relate to guardianship attitudes. Secondly, from an ecological perspective, crime and fear of crime are related to social and physical environment. Thus, territorial identity may play a significant role in residents' perceptions and their intervention experiences. In doing so, this study sought to answer the following research question: what factors influence intervention by potential guardians in residential areas? This paper focuses on Penang, Malaysia, as possibly one of the most ethnically diverse conurbation areas, thereby serving as a particularly suitable testbed for theories about the effects of influencing factors on prosocial behaviour. Before presenting the answer to the research question, a review of the relevant literature is discussed.

\section{LITERATURE REVIEW}

Several researchers advocate the integration of a combination of several theories to explain crime-space relationship. Most theories include routine activities approach, defensible space, social disorganisation theory, vulnerability hypothesis and incivilities thesis. As the focus of this study is on guardianship attitudes that explain why several residential spaces are more defensive than others, this study attempted to partly integrate defensible space, social disorganisation and routine activities approach. Studies show that crime decreases as active guardianship behaviour increases (Reynald, 2009). Research has also found that the physical design of houses, relationships with neighbours, prior victimisation and daily routine activities are crucial factors to facilitate monitoring in residential areas (Moir et al., 2018).

Routine activities approach is a macro-scale theory, which posits that three factors must come together for criminal activity to occur (Cohen \& Felson, 1979). These factors include a suitable target, the absence of capable guardians and a motivated offender. Therefore, a high probability of crime occurs when all three factors occur simultaneously. Ekblom (2019) highlighted the spatial dimension of the routine activities approach and stated that this approach "explains (changing) patterns of crime in terms of (changing) patterns of day-today activity that happen to bring offenders and victims or targets together in the absence of capable guardians; the offenders then seize the opportunities presented". Reynald (2009) stated that the mechanism of supervision is at the heart of the concept of guardianship, which inherently implies control through surveillance. Reynald and Mihinjac (2019) also explicated the role of a guardian as a crime controller or preventer based on the routine activities approach. Natural surveillance refers to the way in which design can maximise the ability of formal 
PLANNING MALAYSIA

Journal of the Malaysia Institute of Planners (2020)

and informal users (social eyes) to monitor surrounding environment (Armitage $\&$ Pascoe, 2016). The primary aim of natural surveillance is to maintain potential criminals under observation of the legitimate users (Abdullah et al., 2013; Marzukhi et al., 2018; Sohn, 2016). Improved lighting is one way that provides positive psychological impacts to users by ensuring good visibility and increasing surveillance (Cho et al., 2019).

Criminological research on community crime rates reflects Shaw and McKay's (1942) influential theory of social disorganisation. In their classic work, Shaw and McKay posited that certain sociostructural factors of a neighbourhood leads to disruption of community social organisation. Social disorganisation refers to the inability of communities to realise common goals, thereby focusing on the effects of crime opportunities in communities (Kubrin \& Weitzer, 2003). The theory assumes that the basis of criminal behaviour depends on a neighbourhood's structural and cultural factors, such that neighbourhoods with a high sense of social cohesion are able to control their surrounding area and experience less crime and fear as a consequence (Frimpong et al., 2018; Rukus \& Warner, 2013; Steenbeek \& Hipp, 2011). Recent Taiwanese research found that social-cultural characteristics of the living environment are related to older adults' behaviour patterns and their physical activities, in which high perceptions of crime may lead not only to increase the time spent on indoor but also to reduce the time spent on outdoor (Lin et al., 2019).

Reynald (2011) asserts that research on residents' willingness to intervene directly in crime prevention can be subsumed within the social disorganisation model, which underscores collective processes that determine levels of informal social control and the users' willingness to intervene on behalf of a common good. As such, the theory focuses on the mediating role of social processes, such as social cohesion and informal social control, on the relationship between neighbourhood structure and crime rates.

According to Newman (Newman, 1972), "defensible space is a model for residential environments which inhibits crime by creating the physical expression of a social fabric that defends itself.... an environment in which latent territoriality and the sense of community in the inhabitants can be translated into responsibility for ensuring a safe, productive and well-maintained living space". On the basis of the theory, territorial functioning can be seen as the critical intervening factor that mediates the relationship between the social and physical environment and the level of criminal activity. Territorial reinforcement assumes that physical design can enhance a sense of proprietorship over a territory. Consequently, users will exert several means of control over these spaces from unwanted intrusion, which in turn result in less crime and fear of crime.

The focus of this study is not the impact of guardianship attitudes on actual crime rate; this study seeks to investigate the most influencing factors that 
Massoomeh Hedayati Marzbali, Aldrin Abdullah \& Mohammad Javad Maghsoodi Tilaki

Surveillability and Guardianship Attitudes: The Role of Multiple Mediators

enhance the potential for guardianship. Advancing the state of knowledge in this area requires innovation in undertaking a highly complete theoretical exploration. The theoretical framework helps in understanding the ways in which factors interact to create enabling conditions for capable guardians. Nonetheless, alerting to the role of perceived risk and social ties as mediators, the function of surveillance on guardianship attitudes when adjusting for the mediating effect remain untested.

A recent study provides a critical overview of the concepts of informal social control and guardianship as these two concepts are usually used interchangeably in the literature (Reynald \& Moir, 2018). Reynald and Moir (2018) argued that although the concept of guardianship bears close resemblance to aspects of informal social control, one core distinction is that informal social control is dependent on neighbourhood social ties, whereas guardianship can be strengthened by social ties at the macro-level. In this way, social cohesion can be considered a mediator in the association between physical design and guardianship.

\section{THEORETICAL FRAMEWORK AND RESEARCH HYPOTHESES}

The current study aims to address the lack of research on contextual factors and guardianship by presenting a unique exploratory empirical investigation of the impact of surveillance and social factors on sense of responsibility for guarding by residents in a multi-ethnic society. Numerous variables treated as contextual factors for the purposes of this study have been used in prior research as indicators of guardianship. Previous empirical studies used target-hardening variables as indicators of guardianship (Miethe \& Meier, 1990; Tewksbury \& Mustaine, 2003). Furthermore, Wilcox et al. (2007) used defensible space variables and social cohesion as measures of physical and social guardianship.

The current study did not focus on guardianship intensity. The survey measured a range of variables that are related to a sense of responsibility for guardianship. The data related to residential guardianship includes guardianship attitudes, perceived risk, social cohesion, surveillance and territorial identity. To date, we are unaware of any research that examines the direct relationship between physical characteristics of the residential environment and guardianship attitudes in a Malaysian context.

Guardianship attitudes are related to people's perception of their relationship to a particular delimited location or their perception of conditions in such a locus, which may involve caretaking and surveillance behaviour. The practical nucleus of the concept of supervision refers to natural surveillance as a cornerstone of Newman's (1972) defensible space concept. Newman (1972) defines defensible space as "a model for residential environments which inhibits 
PLANNING MALAYSIA

Journal of the Malaysia Institute of Planners (2020)

crime by creating the physical expression of a social fabric that defends itself". According to Newman (1972), latent territoriality and sense of responsibility can be translated into residents' responsibility for ensuring a safe and well-maintained living space. This finding explains how surveillance is critical in creating a highly defensive environment. In this way, natural surveillance complements the concept of guardianship from routine activity theory (Reynald, 2011; Reynald \& Moir, 2018).

The current study did not focus on guardianship intensity. The survey measured a range of variables that previous research has shown to be related to sense of responsibility for guardianship, with an emphasis on physical factors related to survivability. The current study seeks to uncover factors that motivate residents to guard their residential spaces. The study model is composed five main constructs: (1) natural surveillance, (2) territorial identity, (3) perceived risk, (4) social cohesion and (5) guardianship attitudes. Table 1 provides the definition of each dimension. The model has two distinguishing characteristics. Firstly, the model is constructed from positive and negative perspectives. Although perceived risk may negatively affect guardianship attitudes, the presence of high levels of surveillance, territorial identity and social contact among residents can buffer this negative effect. Secondly, the model integrates multiple contextual factors (e.g. territorial identity, perceived risk and social cohesion as multiple mediators) to establish the key drivers of guardianship attitudes.

Table 1. Operationalization of the latent variables

\begin{tabular}{|c|c|}
\hline Dimensions & Definitions \\
\hline $\begin{array}{l}\text { Natural } \\
\text { surveillance }\end{array}$ & $\begin{array}{l}\text { The way in which design can maximise the ability of both formal } \\
\text { and informal users to monitor surrounding environment. }\end{array}$ \\
\hline $\begin{array}{l}\text { Territorial } \\
\text { identity }\end{array}$ & $\begin{array}{l}\text { The degree to which the neighbourhood is viewed as a distinct } \\
\text { social and territorial unit. }\end{array}$ \\
\hline Perceived risk & To what extent respondents felt safe in their neighbourhood. \\
\hline Social cohesion & $\begin{array}{l}\text { The extent to which respondents know their neighbours, share } \\
\text { similar interests and take part to prevent crime. }\end{array}$ \\
\hline $\begin{array}{l}\text { Guardianship } \\
\text { attitudes }\end{array}$ & $\begin{array}{l}\text { To what extent respondents respond to crime in different } \\
\text { circumstances through direct and indirect interventions. }\end{array}$ \\
\hline
\end{tabular}

In light of modelling limitation, the intervening effects of territorial identity, social cohesion and perceived risk are usually tested individually as separate mediators, without considering their possible covariation (Kubrin \& Weitzer, 2003). To overcome this limitation, a structural equation modelling approach is employed to examine simultaneously the mediating effects of these three variables by using survey data on the relationship between physical design and 
Massoomeh Hedayati Marzbali, Aldrin Abdullah \& Mohammad Javad Maghsoodi Tilaki

Surveillability and Guardianship Attitudes: The Role of Multiple Mediators

guardianship attitudes in Penang, Malaysia. This study represents the first use of a combination of defensible space and routine activity theory in the literature in a non-Western, multi-ethnic population at the individual level. Furthermore, considering separate mediators is important in social work practice as they provide practitioners with additional targets for intervention. On the basis of defensible space concept and routine activity theory, as well as the discussions, the following research hypotheses were drawn.

H1 Natural surveillance is positively associated with territorial identity.

$\mathrm{H} 2$ Natural surveillance is negatively associated with perceived risk.

H3 Natural surveillance is positively associated with social cohesion.

$\mathrm{H} 4 \quad$ Natural surveillance is positively associated with guardianship attitudes.

H5 Territorial identity is positively associated with guardianship attitudes.

H6 Perceived risk is negatively associated with guardianship attitudes.

H7 Social cohesion is positively associated with guardianship attitudes.

H8 Territorial identity mediates the relationship between natural surveillance and guardianship attitudes.

H9 Perceived risk mediates the relationship between natural surveillance and guardianship attitudes.

H10 Social cohesion mediates the relationship between natural surveillance and guardianship attitudes.

\section{MATERIALS AND METHODS}

\section{SITE SELECTION}

Malaysia is a unique country with a multi-ethnic, multi-religious and multilingual population. Addressing the guardianship attitudes to foster social control is especially important for countries such as Malaysia because of the diverse religious and cultural background of its population. This study constitutes a portion of a large study, which examined the physical characteristics of neighbourhoods and the wellbeing of residents. This study was conducted in Penang, Malaysia, specifically in the Island Glades area, which covered a sample of 247 residents from a systematic sampling method in a homogeneous neighbourhood. As research posits that low social integration exists in multiracial communities (Putnam, 2007), to control differences among three major ethnic groups in Malaysia, a homogenous neighbourhood was selected.

Island Glades, a typical medium class neighbourhood, was formerly a plantation land in the 1960s, which was rapidly transformed into the residential neighbourhood as it is now. Hence, Island Glades stands as one of the oldest developments on the island of Penang and is still popular to this day for its central location, with new developments rising on its outskirt. Houses located within 
Island Glades are typically double-storey, with several single-storey houses. The area consists of approximately 1,700 dwelling units.

To capture the information on neighbourhood social and physical environments, on-site observation was conducted, followed by a questionnaire survey. Direct observations enable obtaining a comprehensive and objective representation of physical characteristics of neighbourhoods (Paquet et al., 2010). This study utilises a systematic sampling method to select samples from the population. The surveys were conducted in English and Malay based on the respondent's preference, and they required approximately 15 minutes to complete. To ensure inter-rater reliability, a pair of observers gathered observations from a small number of randomly-selected residents. An analysis of inter-rater reliability was performed to assess the degree to which observers consistently assigned the levels of indicators. The resulting kappa indicated substantial agreement and therefore the ratings were deemed as adequate for use to test the hypotheses in the present study. The study focused on residents of landed properties, as these were the predominant type of dwelling in the study area. Table 2 depicts the demographic characteristics of the respondents.

Table 2. Respondents' demographic characteristics

\begin{tabular}{lll}
\hline Demographic variables & Categories & Island Glades (n=247) \\
\hline Ownership & Owner & $215(87.0 \%)$ \\
& Tenant & $19(7.7 \%)$ \\
Gender & Others & $13(5.3 \%)$ \\
Marital status & Male & $123(49.8 \%)$ \\
Main wage earner & Female & $124(50.2 \%)$ \\
& Single, widowed or separated & $57(23.1 \%)$ \\
& Yarried or living as married & $190(76.9 \%)$ \\
Education & No & $99(40.1 \%)$ \\
& Not applicable & $137(55.5 \%)$ \\
& University/college & $11(4.5 \%)$ \\
& Secondary education & $125(50.6 \%)$ \\
& Primary education & $102(41.3 \%)$ \\
Occupation & Non formal education & $6(2.4 \%)$ \\
& Self-employed & $43(17.4 \%)$ \\
& Private sector employee & $73(29.6 \%)$ \\
& Public sector employee & $16(6.5 \%)$ \\
& Retiree & $52(21.1 \%)$
\end{tabular}


Massoomeh Hedayati Marzbali, Aldrin Abdullah \& Mohammad Javad Maghsoodi Tilaki Surveillability and Guardianship Attitudes: The Role of Multiple Mediators

\begin{tabular}{lll}
\hline Demographic variables & Categories & Island Glades (n=247) \\
\hline \multirow{3}{*}{ Length of residence } & Unemployed & $4(1.6 \%)$ \\
& Others & $59(23.9 \%)$ \\
& Less than 5 years & $30(12.1 \%)$ \\
& $5-9$ years & $35(14.2 \%)$ \\
Ethnicity & 10 years and over & $182(73.7 \%)$ \\
& Malay & $9(3.6 \%)$ \\
Household income & Chinese & $229(92.7 \%)$ \\
& Indian & $9(3.6 \%)$ \\
& Less than RM 3000 & $37(15.0 \%)$ \\
& From RM 3001-RM 5000 & $69(27.9 \%)$ \\
& From RM 5001-RM 7000 & $65(26.3 \%)$ \\
& From RM 7001-RM 9000 & $50(20.2 \%)$ \\
& RM 9001 and above & $26(10.5 \%)$ \\
\hline
\end{tabular}

\section{SURVEY INSTRUMENT}

The study is quantitative in nature, thereby prompting residents to respond to a set of self-administered questionnaires. Apart from providing their demographic information, participants responded to 21 statements that reflect territorial identity, perceived risk, social cohesion and guardianship attitudes. Table 3 presents the study variables with respective indicators. Items were adapted based on the work of Greenberg et al. (1982). Social cohesion items were adapted from the work of Hedayati et al. (2015), Reynald (2011), and Sampson et al. (1997) on a seven-pint Likert scale (1=strongly disagree, $7=$ strongly agree). Items of perceived risk were adapted from Abdullah et al. (2016), Franklin et al. (2008) and Mason et al. (2013) on a five-point Likert scale ( $1=$ very safe, $5=$ very unsafe). Guardianship attitude was measured on seven-point Likert scale ( $1=$ strongly disagree, $7=$ strongly agree) and was adapted based on the work of Reynald (2011). Surveillance is classified into two categories: lighting and visibility (Abdullah et al., 2013; Marzbali et al., 2019). Lighting was measured on a fivepoint Likert scale ( $1=$ extremely not satisfied, $5=$ extremely satisfied) and referred to the quality of lighting at house level. Four statements were employed to measure the level of visibility, referring to the degree of possibility of places being overlooked by residents and outsiders based on a five-point Likert scale $(1=$ very poor, $5=$ very good $)$ 
PLANNING MALAYSIA

Journal of the Malaysia Institute of Planners (2020)

Table 3. Study variables with respective indicators

\section{Construct \\ Territorial Identity}

Perceived risk

Guardianship attitudes

Item Description

TI1 I know the name of my neighbourhood.

TI2 I can easily draw the boundary of my neighbourhood on the map.

TI3 There is natural surveillance by people or activities through various land uses (e.g., neighbourhood watch).

TI4 There is formal surveillance in my neighbourhood (e.g., CCTV, police patrol).

Social cohesion SC1 I know my neighbours on my street.

SC2 I interact with my neighbours fairly often.

SC3 I will try to assist my neighbours if I see them in trouble.

SC4 I am confident that my neighbours will assist me if I need help.

SC5 I do my part to prevent crime and disorder on my street.

SC6 My neighbours do their part to prevent crime and disorder on this neighbourhood.

PR1 How safe do you feel walking alone in your street during the day?

PR2 How safe do you feel walking alone in your street after dark?

PR3 How safe do you feel walking alone in this neighbourhood during the day?

PR4 How safe do you feel walking alone in this neighbourhood after dark?

PR5 How safe do you feel when you are in home alone at night?

PR6 How safe do you feel when you are in a park or playground in your neighbourhood during the day?

GA1 If I see a crime in progress, I would take some action.

GA2 Dealing with crimes is the responsibility of ordinary citizens.

GA3 I will do what I can to protect my neighbours from crime.

GA4 I believe I have a role to play in preventing crime.

GA5 I keep an eye on what occurs in front of my house daily. 
Massoomeh Hedayati Marzbali, Aldrin Abdullah \& Mohammad Javad Maghsoodi Tilaki Surveillability and Guardianship Attitudes: The Role of Multiple Mediators

\begin{tabular}{lll}
\hline Construct & Item & Description \\
\hline Visibility & Vis1 & $\begin{array}{l}\text { 1. All doors and windows at the front façade are visible } \\
\text { from the street. }\end{array}$ \\
Vis2 & $\begin{array}{l}\text { 2. No places are concealed by fences in the yard from } \\
\text { the main entrance. }\end{array}$ \\
Vis3 & $\begin{array}{l}\text { 3. All spaces between houses are visible. } \\
\text { Vis4 }\end{array}$ & $\begin{array}{l}\text { 4. Shrubs are kept to a maximum of } 90 \mathrm{~cm} \text { in height. } \\
\text { Lighting }\end{array}$ \\
& $\begin{array}{l}\text { 1. Lighting facilities at the main entrance } \\
\text { 2. Lighting around the building } \\
\text { 3. The level of lighting in the yard area }\end{array}$ \\
\hline
\end{tabular}

\section{STATISTICAL ANALYSIS}

The proposed model and hypothesis testing are conducted by using Partial Least Squares (PLS) analysis with the SmartPLS 3 software (Ringle et al., 2015). PLS was chosen because of its appropriateness to the use of hierarchical variable model and the exploratory nature of this study. Likewise, PLS is highly appropriate when a research model is at its infancy, and it avoids the limitations of covariance-based SEM, such as sample size and restrictions stemming from modelling complexity (Wetzels et al., 2009). Nonparametric bootstrapping was applied to test the significance of the path coefficient among latent variables as well as between the latent variables and respective manifest variables. The study tested the measurement model (validity and reliability) and structural model (testing the relationship among variables) to finalise the outcome. Wetzels et al. (2009) suggested that the manifest variables will be used twice, for the first-order latent variables and second-order latent variable (known as 'secondary loadings', i.e. natural surveillance). Hedayati-Marzbali et al. (2016) suggested that natural surveillance is a second-order latent construct which consists of visibility and lighting as first-order constructs. In addition to the assessment of the path coefficient, there are four criteria that need to be tested to examine the structural model: coefficient of determination $\left(R^{2}\right)$, effect size $\left(f^{2}\right)$, variance inflation factor (VIF) and predictive relevance $\left(Q^{2}\right)$.

\section{RESULTS AND FINDINGS \\ MEASUREMENT MODEL RESULTS}

The measurement model evaluation requires outer loadings, convergent validity, composite reliability and discriminant validity (Tables 4 and 5). The threshold value of composite reliability for a given construct is 0.7 (Bagozzi \& Yi, 1988). Table 4 posits that all the constructs have composite reliability value more than 0.70 . The measure of convergent validity is the average variance extracted for which the threshold value is 0.5 (Fornell \& Larcker, 1981). Consequently, all the constructs possess convergent validity (Table 4 ). 
PLANNING MALAYSIA

Journal of the Malaysia Institute of Planners (2020)

Table 4. The measurement model results for the latent constructs

\begin{tabular}{|c|c|c|c|c|c|}
\hline Construct & Items & Loadings & $\begin{array}{l}\text { Composite } \\
\text { reliability } \\
\text { (CR) }\end{array}$ & $t$ value & $\begin{array}{l}\text { Average } \\
\text { variance } \\
\text { extracted } \\
\text { (AVE) }\end{array}$ \\
\hline \multirow[t]{3}{*}{ Lighting } & Lit1 & 0.929 & \multirow[t]{3}{*}{0.952} & $15.489 * * *$ & \multirow[t]{3}{*}{0.869} \\
\hline & Lit3 & 0.968 & & $15.774 * * *$ & \\
\hline & Lit4 & 0.900 & & $14.815^{* * *}$ & \\
\hline \multirow[t]{4}{*}{ Visibility } & Vis2 & 0.953 & \multirow[t]{4}{*}{0.947} & $142.132 * * *$ & \multirow[t]{4}{*}{0.818} \\
\hline & Vis 3 & 0.954 & & $167.297 * * *$ & \\
\hline & Vis 4 & 0.968 & & $243.565 * * *$ & \\
\hline & Vis 5 & 0.717 & & $20.330 * * *$ & \\
\hline \multirow[t]{4}{*}{ Territorial identity } & TI1 & 0.530 & \multirow[t]{4}{*}{0.835} & $5.947 * * *$ & \multirow[t]{4}{*}{0.565} \\
\hline & $\mathrm{TI} 2$ & 0.755 & & $12.290 * * *$ & \\
\hline & TI3 & 0.853 & & $33.576 * * *$ & \\
\hline & TI4 & 0.826 & & $16.590 * * *$ & \\
\hline \multirow[t]{6}{*}{ Perceived risk } & PR1 & 0.847 & \multirow[t]{6}{*}{0.910} & $8.655^{* * *}$ & \multirow[t]{6}{*}{0.630} \\
\hline & PR2 & 0.683 & & $4.507 * * *$ & \\
\hline & PR3 & 0.839 & & $7.955 * * *$ & \\
\hline & PR4 & 0.703 & & $4.748 * * *$ & \\
\hline & PR5 & 0.786 & & $11.298 * * *$ & \\
\hline & PR6 & 0.883 & & $12.638 * * *$ & \\
\hline \multirow[t]{6}{*}{ Social cohesion } & $\mathrm{SC} 1$ & 0.893 & \multirow[t]{6}{*}{0.946} & $62.756 * * *$ & \multirow[t]{6}{*}{0.747} \\
\hline & $\mathrm{SC} 2$ & 0.919 & & $56.915^{* * *}$ & \\
\hline & $\mathrm{SC} 3$ & 0.936 & & $105.827 * * *$ & \\
\hline & $\mathrm{SC} 4$ & 0.852 & & $41.441 * * *$ & \\
\hline & SC5 & 0.806 & & $26.820 * * *$ & \\
\hline & SC6 & 0.769 & & $20.097 * * *$ & \\
\hline \multirow[t]{5}{*}{ Guardianship attitudes } & GA1 & 0.883 & \multirow[t]{5}{*}{0.912} & $37.258 * * *$ & \multirow[t]{5}{*}{0.677} \\
\hline & GA2 & 0.864 & & $28.711 * * *$ & \\
\hline & GA3 & 0.847 & & $29.401 * * *$ & \\
\hline & GA4 & 0.838 & & $23.586^{* * *}$ & \\
\hline & GA5 & 0.660 & & $14.177 * * *$ & \\
\hline
\end{tabular}

Note. ${ }^{* * *} p<.01$

The SmartPLS 3 software offers a unique measure to establish the discriminant validity for a pair of two constructs: heterotrait-monotrait (HTMT) ratio and confidence interval up. The liberal threshold values for the HTMT ratio and corresponding confidence interval up are less than 0.85 and 1 , respectively 
Massoomeh Hedayati Marzbali, Aldrin Abdullah \& Mohammad Javad Maghsoodi Tilaki

Surveillability and Guardianship Attitudes: The Role of Multiple Mediators

(Henseler et al., 2015). Consequently, HTMT ratios and the corresponding confidence intervals up for each pair are less than 0.85 and 1 , respectively (Table $5)$. Hence, the model possesses discriminant validity.

Table 5. Heterotrait-Monotrait (HTMT)

\begin{tabular}{|c|c|c|c|c|c|}
\hline Lighting & $\begin{array}{l}\text { Guardianship } \\
\text { attitudes } \\
0.313 \\
\text { CI.90 ( } 0.200 \text {, } \\
0.422)\end{array}$ & Lighting & $\begin{array}{l}\text { Perceived } \\
\text { risk }\end{array}$ & $\begin{array}{l}\text { Social } \\
\text { cohesion }\end{array}$ & $\begin{array}{l}\text { Territorial } \\
\text { identity }\end{array}$ \\
\hline $\begin{array}{l}\text { Perceived } \\
\text { risk }\end{array}$ & $\begin{array}{l}0.116 \\
\text { CI.90 }(0.090 \text {, } \\
0.218)\end{array}$ & $\begin{array}{l}0.073 \\
\text { CI.90 } \\
(0.055 \\
0.165)\end{array}$ & & & \\
\hline $\begin{array}{l}\text { Social } \\
\text { cohesion }\end{array}$ & $\begin{array}{l}0.584 \\
\text { CI.90 (0.474, } \\
0.692)\end{array}$ & $\begin{array}{l}0.266 \\
\text { CI.90 } \\
(0.146, \\
0.400)\end{array}$ & $\begin{array}{l}0.255 \\
\text { CI.90 } \\
(0.184, \\
0.376)\end{array}$ & & \\
\hline $\begin{array}{l}\text { Territorial } \\
\text { identity }\end{array}$ & $\begin{array}{l}0.400 \\
\text { CI.90 ( } 0.264 \text {, } \\
0.550)\end{array}$ & $\begin{array}{l}0.361 \\
\text { CI.90 } \\
(0.217, \\
0.489)\end{array}$ & $\begin{array}{l}0.196 \\
\text { CI.90 } \\
(0.132, \\
0.312)\end{array}$ & $\begin{array}{l}0.338 \\
\text { CI.90 } \\
(0.213, \\
0.468)\end{array}$ & \\
\hline Visibility & $\begin{array}{l}0.084 \\
\text { CI.90 (0.062, } \\
0.198)\end{array}$ & $\begin{array}{l}0.161 \\
\text { CI.90 } \\
(0.054, \\
0.284)\end{array}$ & $\begin{array}{l}0.199 \\
\text { CI.90 } \\
(0.095, \\
0.326)\end{array}$ & $\begin{array}{l}0.193 \\
\text { CI.90 } \\
(0.087, \\
0.317)\end{array}$ & $\begin{array}{l}0.132 \\
\text { CI.90 (0.067, } \\
0.283)\end{array}$ \\
\hline
\end{tabular}

Additionally, the possibility of common method variance was examined by using Harman's one-factor test (Podsakoff et al., 2003). According to these authors, common method variance occurs when only one factor emerges from a factor analysis or when the first factor explains more than $50 \%$ of the variance. In this light, all the items for the constructs were introduced into a factor analysis and the unrotated matrix indicates that the first factor explains $24 \%$ of the variance. As such, common method variance is not an issue in this study.

\section{AN ASSESSMENT OF THE HIERARCHICAL SURVEILLANCE CONSTRUCT}

This study specifies natural surveillance as a second-order construct, which is composed of two first-order reflective constructs (lighting and visibility) representing seven items. The degree of explained variance of this hierarchical construct is reflected in its components: lighting $\left(R^{2}=46.8 \%\right)$ and visibility $\left(R^{2}=\right.$ $67.9 \%)$. The entire path coefficient from natural surveillance to its dimensions is significant at $p<0.01$. 


\section{AN ASSESSMENT OF THE STRUCTURAL MODEL \\ Direct Effects}

Table 6 depicts the results of path analysis used to test the hypothesis of direct effects among latent variables. The results indicated that the impacts of natural surveillance on territorial identity $(\beta=0.259, p<0.01)$ and social cohesion $(\beta=$ $0.231, p<0.01)$ are positive and significant. In line with previous studies, the results suggest that additional opportunities for surveillance are associated with a great sense of territorial identity and social cohesion. Moreover, in line with previous studies, the results also indicated a negative and significant association between natural surveillance and perceived risk $(\beta=-0.181, p<0.01)$, where high levels of surveillance are associated with low levels of risk perceptions. However, the direct association between natural surveillance and guardianship attitudes is not significant $(\beta=0.031, p>0.05)$. Hence, the results support H1, $\mathrm{H} 2$ and $\mathrm{H} 3$, but not $\mathrm{H} 4$.

Moreover, territorial identity has a positive and significant impact on guardianship attitudes $(\beta=0.197, p<0.01)$ and social cohesion also has a positive and significant impact on guardianship attitudes $(\beta=0.590, p<0.01)$. Surprisingly, although we hypothesised a negative association between perceived risk and guardianship attitudes, the results show a positive and significant association between these two variables $(\beta=0.124, p<0.01)$, which demonstrates that people who perceive high levels of risk are likely to rate their guardianship attitudes positively. The results support $\mathrm{H} 5$ and H7, but not H6. Although not hypothesised, the result indicates that high perceived risk is associated with low social cohesion. The $R^{2}$ value for guardianship attitudes is 0.433 .

Table 6. Path coefficient and hypothesis testing (direct effects)

\begin{tabular}{lllllll}
\hline Hs & Relationship & $\boldsymbol{\beta}$ & $\boldsymbol{t}$ value & Decision & $\boldsymbol{f}^{\mathbf{2}}$ & $\boldsymbol{V I F}$ \\
\hline $\mathrm{H} 1$ & $\mathrm{NS} \rightarrow \mathrm{TI}$ & 0.259 & $4.053^{* * *}$ & Supported & 0.072 (Small) & 1.000 \\
$\mathrm{H} 2$ & $\mathrm{NS} \rightarrow \mathrm{PR}$ & - & $2.940^{* * *}$ & Supported & 0.034 (Small) & 1.000 \\
& & 0.181 & & & & \\
$\mathrm{H} 3$ & $\mathrm{NS} \rightarrow \mathrm{SC}$ & 0.231 & $3.923^{* * *}$ & Supported & 0.060 (Small) & 1.034 \\
$\mathrm{H} 4$ & $\mathrm{NS} \rightarrow \mathrm{GA}$ & 0.031 & 0.605 & $\begin{array}{l}\text { Not } \\
\text { supported }\end{array}$ & 0.001 & 1.141 \\
& & & & & \\
$\mathrm{H} 5$ & $\mathrm{TI} \rightarrow \mathrm{GA}$ & 0.197 & $3.631^{* * *}$ & Supported & 0.060 (Small) & 1.138 \\
$\mathrm{H} 6$ & $\mathrm{PR} \rightarrow \mathrm{GA}$ & 0.124 & $1.989^{* * *}$ & Supported & 0.024 (Small) & 1.106 \\
$\mathrm{H} 7$ & $\mathrm{SC} \rightarrow \mathrm{GA}$ & 0.590 & $12.292^{* * *}$ & Supported & 0.505 & 1.217 \\
& & & & & (Substantial) & \\
\hline
\end{tabular}

Beta $=$ regression weight, $t$ values are computed through bootstrapping procedure with 247 cases and 1,000 samples; *** $p<0.001$ 
Massoomeh Hedayati Marzbali, Aldrin Abdullah \& Mohammad Javad Maghsoodi Tilaki

Surveillability and Guardianship Attitudes: The Role of Multiple Mediators

\section{Indirect Effects}

This study estimates three mediating relationships as shown in Figure 1. Table 7 depicts the results of path analysis used to test the hypothesis of indirect effects. The $t$ values were computed through a bootstrapping procedure suggested by Hayes (2009) with 1,000 samples. To estimate the significance of the indirect effect, numerous researchers employed the Sobel test. One limitation of the Sobel test is that it requires a normal sampling distribution of the indirect effect (Hayes, 2009), whereas the indirect effect (ab) sampling distribution tends to be asymmetric with non-zero values for skewness and kurtosis (Stone \& Sobel, 1990). According to Hayes (2009), tests that assume normality of the sampling distribution should not be used to assess indirect effects and suggests the use of a bootstrapping procedure as an alternative approach to test indirect effects. The $t$ values for direct and indirect effects were computed through a bootstrapping procedure with 1,000 samples. The $t$ values for indirect effects are obtained by dividing the $a b$ by the standard error (SE) of the indirect effect. The SE is the standard deviation of the repeated bootstrap estimates of the indirect effect. Table 7 shows that the $t$ values of two indirect effects (H8 and H10) are significant at the 0.05 level. Therefore, the results support $\mathrm{H} 8$ and H10m but not H9.

Table 7. Hypothesis testing (indirect effects)

\begin{tabular}{|c|c|c|c|c|c|c|c|}
\hline Hs & Relationship & $\begin{array}{l}\text { Predictor- } \\
\operatorname{criterion}(\beta)\end{array}$ & $\begin{array}{l}\text { Predictor- } \\
\text { mediator } \\
(\beta)\end{array}$ & $\begin{array}{l}\text { Mediator- } \\
\text { criterion } \\
(\beta)\end{array}$ & $t$ value & Decision & $\begin{array}{l}\text { VAF } \\
(\%)\end{array}$ \\
\hline H8 & $\mathrm{NS} \rightarrow \mathrm{TI} \rightarrow \mathrm{GA}$ & 0.031 & $0.259 * * *$ & $0.197 * * *$ & $2.673 * * *$ & Supported & 22.98 \\
\hline H9 & $\mathrm{NS} \rightarrow \mathrm{PR} \rightarrow \mathrm{GA}$ & 0.031 & $-0.181 * * *$ & $0.124 * *$ & 1.401 & $\begin{array}{l}\text { Not } \\
\text { Supported }\end{array}$ & -- \\
\hline H10 & $\mathrm{NS} \rightarrow \mathrm{SC} \rightarrow \mathrm{GA}$ & 0.031 & $0.231 * * *$ & $0.590 * * *$ & $4.542 * * *$ & Supported & 61.39 \\
\hline
\end{tabular}

The variance accounted for (VAF) was calculated to estimate the size of the indirect effect by dividing the indirect effect by the total effect (Shrout \& Bolger, 2002). Table 7 shows that the territorial identity explained approximately $23 \%$ of the variance in mediating the relationship between natural surveillance and guardianship attitude and the magnitude is considered partial (Hair et al., 2013). The VAF value indicates that approximately $61 \%$ of the total effect of natural surveillance on guardianship attitude is explained by the partial mediating effect of social cohesion.

On the basis of the $R^{2}$ values, result reveals that approximately $7 \%$ and $3 \%$ of the variance in territorial identity and perceived risk are explained by natural surveillance, whereas natural surveillance and perceived risk explain approximately $14 \%$ of the variance in social cohesion. However, natural surveillance (indirectly), territorial identity, perceived risk and social cohesion reasonably explain $43 \%$ of the variance in guardianship attitude. The purpose of 
calculating the effect size $\left(f^{2}\right)$ is to estimate the extent of the influence of an independent latent variable on the dependent variable. Effect size is based on the change in the coefficient of determination $\left(R^{2}\right)$. According to Chin (1998), the values of $0.02,0.15$ and 0.35 represent the level of effect size as small, moderate and substantial, respectively. Table 6 shows that the $f^{2}$ for territorial identity, perceived risk and social cohesion on guardianship attitudes were $0.060,0.024$ and 0.505 , respectively. Thus, social cohesion has a substantial impact on guardianship attitude.

Multicollinearity among the variables was also evaluated in the model and did not find any cause for concern by using the criteria of variance inflation factor, which were (Table 6) all below the suggested threshold of 5.00 (Hair et al., 2013). Hair et al. (2017) suggest that the predictive relevance of the model through the blindfolding procedure be examined. The $Q^{2}$ values for territorial identity $\left(Q^{2}=0.031\right)$, perceived risk $\left(Q^{2}=0.014\right)$, social cohesion $\left(Q^{2}=0.094\right)$ and guardianship attitude $\left(Q^{2}=0.214\right)$ are $>0$, suggesting that the model has sufficient predictive relevance.

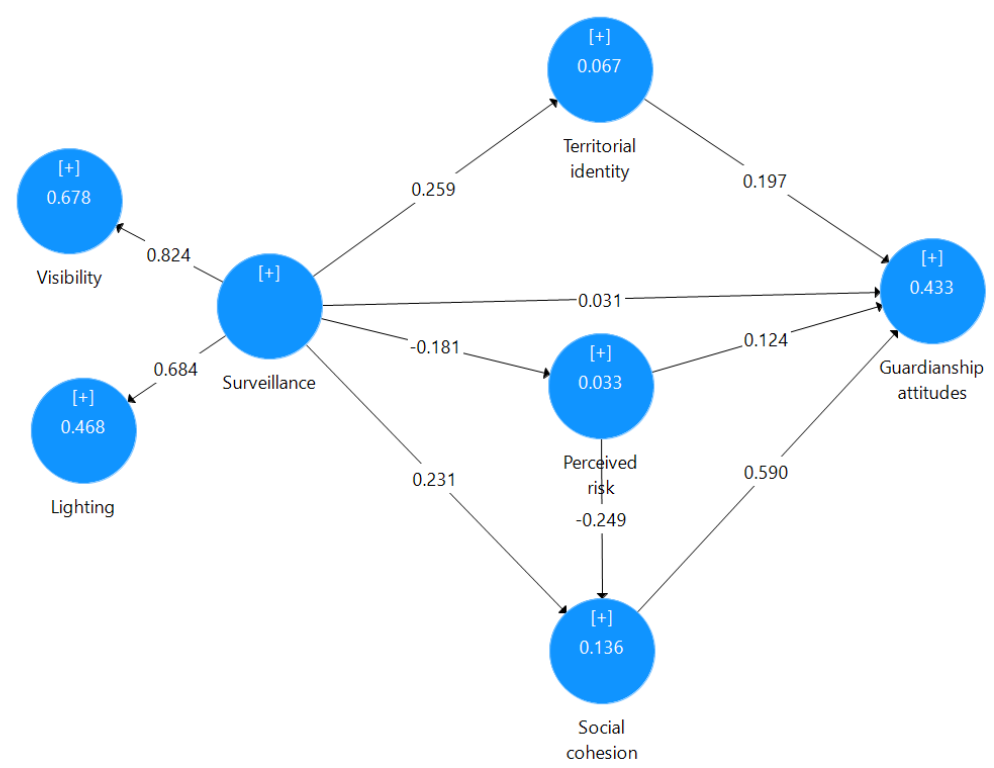

Figure 1. The parameter estimates of the PLS analysis

\section{CONCLUSIONS}

The current study aims at investigating the impact of surveillance and social factors on sense of responsibility for guardianship by residents in a multi-ethnic 
Massoomeh Hedayati Marzbali, Aldrin Abdullah \& Mohammad Javad Maghsoodi Tilaki

Surveillability and Guardianship Attitudes: The Role of Multiple Mediators

society. This study investigates the role that spatio-physical and social factors play in facilitating monitoring and intervention among potential guardians against criminal behaviour in residential areas in Malaysia. Although surveillance was theoretically developed to predict guardianship attitude, mediating roles of territorial identity, perceived risk and social cohesion on the path between surveillance and guardianship attitude were also examined in an exploratory sense. The results reveal that the direct effects for natural surveillance on guardianship attitude may not be as straightforward as presumed in the literature and this relationship was mediated through territorial identity, and an increase in social cohesion.

Conceptually, the current study extends this line of research by assessing the effect of natural surveillance, territorial identity, perceived risk and social cohesion on guardianship attitude in a multi-ethnic urban society. Furthermore, surveillance helps to reduce perceived risk among residents, whereas high levels of surveillance are related to high levels of territorial identity and social cohesion. Furthermore, surveillance helps to reduce perceived risk among residents and consequently, to enhance social cohesion among residents. This effect can contribute to an increase in health and well-being, as research found that social cohesion enhances optimism towards health (Marzbali et al., 2016).

Turning our attention away from the traditional focus on the role of the environment in creating opportunities for supervision, this study attempted to examine the most influential factors in explaining guardianship attitude. Although supervision is a fundamental dimension of residential guardianship that is critically affected by opportunities provided by environmental design and layout, research shows that even when available residential guardians have the opportunity to monitor their surroundings, supervision is not guaranteed (Barr \& Pease, 1992; Reynald, 2010). These findings provide several interesting insights into social disorganisation theory at the individual level. Consistent with a large body of research (e.g. (Hedayati-Marzbali et al., 2016; Sampson et al., 1997)), the findings reveal that residents with strong social ties and territorial identity are likely to engage in guardianship attitudes. Contrary to expectations, a positive relationship exists between perceived risk and guardianship attitudes. The results also indicated that although guardianship attitudes can be strengthened by social ties and territorial identity, it does not necessarily require low perceptions of risk to function effectively. Although only a few studies attempted to measure actual supervision by residents when they are at home as a form of guardianship (Reynald, 2011; Reynald \& Elffers, 2009), limited studies have focused on guardianship attitudes and its association with risk perceptions and social ties (Reynald, 2018). 
PLANNING MALAYSIA

Journal of the Malaysia Institute of Planners (2020)

This research has important implications for crime prevention in residential contexts as it illustrates the individual factors that predict guardianship attitudes. The findings of the current study can be used by planners and those who are involved in community policies to design crime prevention strategies aimed at creating safe communities by increasing the likelihood of guardianship attitudes among residents. The implication is that opportunities for natural surveillance provided by the physical environment contribute to enhance territorial identity and social cohesion, and consequently the likelihood of guardianship attitudes. Social cohesion is the most influential factor in shaping opportunities for capable guardianship in the study area. This finding brings to focus the importance of high social cohesion among residents to their overall willingness and intention to intervene in disorderly situations.

\section{RECOMMENDATIONS FOR FUTURE RESEARCH}

Although our findings are generally consistent across neighbourhoods, several points can be improved. As the results reveal that no direct association exists between natural surveillance and guardianship attitudes, it is a call for further research to understand the dynamics of surveillance and guardianship attitudes better in neighbourhoods. The second limitation refers to the ethnic composition of the study context. Ethnic composition contributes to the ability of a community to control the neighbourhood environment (Sampson \& Groves, 1989), and variations in ethnic heterogeneity will increase disorderly conduct by weakening informal control (Hedayati et al., 2015). Similarly, Steenbeek and Hipp (2011) found that high ethnic heterogeneity leads to increased disorder and decreased cohesion, which in turn affect the potential for social control. Likewise, empirical research in a Malaysian context found that residents from different cultures perceive social environment differently, given that perceived neighbouring behaviour, territorial attitudes and perceived risk vary across cultures (Hedayati et al., 2015). As the study was conducted in a homogenous neighbourhood, future research may bring new insights to the body of knowledge by focusing on homogenous and heterogeneous neighbourhoods. It also anticipates that future research will continue to explore this complex question by examining ethnic relations. It is concluded that organising community-based activities will help strengthen community ties, thereby creating substantial willingness among residents to intervene for the common good.

\section{ACKNOWLEDGEMENTS}

The authors would like to thank Universiti Sains Malaysia for financially supporting this research under Research University Grant (RUI, NO. 1001/PPBGN/8016079). 
Massoomeh Hedayati Marzbali, Aldrin Abdullah \& Mohammad Javad Maghsoodi Tilaki

Surveillability and Guardianship Attitudes: The Role of Multiple Mediators

\section{REFERENCES}

Abdullah, A., Hedayati Marzbali, M., \& Maghsoodi Tilaki, M. J. (2013). Predicting the Influence of CPTED on Perceived Neighbourhood Cohesion: Considering Differences across Age. Journal of Environmental Psychology, 36(4), 54-64.

Abdullah, A., Hedayati Marzbali, M., Ramayah, T., Bahauddin, A., \& Maghsoodi Tilaki, M. J. (2016). Territorial functioning and fear of crime: Testing for mediation in structural equation modeling. Security Journal, 29(3), 461-484. doi: $10.1057 /$ sj. 2013.40

Armitage, R., \& Joyce, C. (2017). "Why my house?" - Exploring the influence of residential housing design on burglar decision-making. In R. Armitage \& P. Ekblom (Eds.), Re-building Crime Prevention through Environmental Design (CPTED): Taylor \& Francis.

Armitage, R., \& Pascoe, T. (2016). Crime Prevention through Environmental Design. In Handbook of Crime Prevention and Citizen Security For Latin America. Arévalo: Ediciones Didot.

Bagozzi, R. P., \& Yi, Y. (1988). On the evaluation of structural equation models. Journal of the Academy of Marketing Science, 16(1), 74-94.

Barr, R., \& Pease, K. (1992). A place for every crime and every crime in its place: An alternative perspective on crime displacement. In D. J. Evans, N. F. Fyfe, \& D. T. Herbert (Eds.), Crime Policing and Place: Essays in Environmental Criminology. London: Routledge.

Chin, W. W. (1998). The partial least squares approach for structural equation modeling. In G. A. Marcoulides (Ed.), Modern methods for business research (pp. 295336). Mahwah, New Jersey, USA: Lawrence Erlbaum.

Cho, Y., Jeong, H., Choi, A., \& Sung, M. (2019). Design of a Connected Security Lighting System for Pedestrian Safety in Smart Cities. Sustainability, 11(5), 1308.

Cohen, L. E., \& Felson, M. (1979). Social change and crime rate trends: A routine activity approach. American Sociological Review, 44(4), 588-608.

Comstocka, N., Dickinsonb, L. M., Marshallc, J. A., Soobaderd, M.-J., Turbine, M. S., Buchenauf, M., \& Litt, J. S. (2010). Neighborhood attachment and its correlates: Exploring neighborhood conditions, collective efficacy and gardening. Journal of Environmental Psychology, 30(4), 435-442.

Ekblom, P. (2019). Sharpening up CPTED - towards an ontology based on crime science and ecology. In R. Armitage \& P. Ekblom (Eds.), Rebuilding Crime Prevention Through Environmental Design: Strengthening the Links with Crime Science (pp. 75-108). Oxan, UK: Routledge.

Felson, M. (2006). Crime and nature. Thousand Oaks, CA: Sage.

Fornell, C., \& Larcker, D. F. (1981). Evaluating structural equation models with unobservable variables and measurement error. Journal of Marketing research, 18(1), 39-50.

Franklin, T. W., Franklin, C. A., \& Fearn, N. E. (2008). A multilevel analysis of the vulnerability, disorder, and social integration models of fear of crime. Social Justice Research, 21(2), 204-227. 
Frimpong, L. K., Oteng-Ababio, M., Owusu, G., \& Wrigley-Asante, C. (2018). Collective efficacy and fear of crime in urban neighbourhoods in Ghana. Safer Communities, 17(3), 167-181.

Greenberg, S. W., Rohe, W. M., \& Williams, J. R. (1982). Safety in urban neighborhoods: A comparison of physical characteristics and informal territorial control in high and low crime neighborhoods. Population \& Environment, 5(3), 141-165.

Hair, J. F., Ringle, C. M., \& Sarstedt, M. (2013). Partial least squares structural equation modeling: Rigorous applications, better results and higher acceptance.

Hair Jr, J. F., Hult, G. T. M., Ringle, C., \& Sarstedt, M. (2017). A primer on partial least squares structural equation modeling (PLS-SEM) (Second ed.). United States of America: Sage publications.

Hayes, A. F. (2009). Beyond Baron and Kenny: Statistical mediation analysis in the new millennium. Communication Monographs, 76(4), 408-420.

Hedayati-Marzbali, M., Abdullah, A., Ignatius, J., \& Tilaki, M. J. M. (2016). Examining the effects of crime prevention through environmental design (CPTED) on Residential Burglary. International Journal of Law, Crime and Justice, 46(3), 86-102.

Hedayati, M., Abdullah, A., \& Maghsoodi Tilaki, M. J. (2015). Neighbouring behaviour, ethnic relations and informal control: a multigroup analysis. Safer Communities, 14(2), 80 - 94.

Henseler, J., Ringle, C. M., \& Sarstedt, M. (2015). A new criterion for assessing discriminant validity in variance-based structural equation modeling. Journal of the Academy of Marketing Science, 43(1), 115-135.

Hollis-Peel, M. E., \& Welsh, B. C. (2014). What makes a guardian capable? A test of guardianship in action. Security Journal, 27(3), 320-337.

Kubrin, C. E., \& Weitzer, R. (2003). New directions in social disorganization theory. Journal of Research in Crime and Delinquency, 40(4), 374-402.

Lin, C.-Y., Park, J.-H., Hsueh, M.-C., Lai, T.-F., \& Liao, Y. (2019). Are Area-Level Crimes Associated with Older Adults' Physical Activity and Sedentary Behavior? Sustainability, 11(9), 2454.

MacDonald, J. E., \& Gifford, R. (1989). Territorial cues and defensible space theory: The burglar's point of view. Journal of Environmental Psychology, 9(3), 193-205.

Marzbali, M. H., Abdullah, A., Razak, N. A., \& Tilaki, M. J. M. (2012). The Influence of Crime Prevention Through Environmental Design on Victimisation and Fear of Crime. Journal of Environmental Psychology, 32(2), 79-88. doi:10.1016/j.jenvp.2011.12.005

Marzbali, M. H., Abdullah, A., \& Tilaki, M. J. M. (2016). The effectiveness of interventions in the built environment for improving health by addressing fear of crime. International Journal of Law, Crime and Justice, 45(2), 120-140. doi:10.1016/j.ijlcj.2015.12.002

Marzbali, M. H., Abdullah, A., \& Tilaki, M. J. M. (2019). Crime Prevention Through Environmental Design (CPTED) in Malaysia: development of a tool to measure CPTED implementation in residential settings. In R. Armitage \& P. Ekblom (Eds.), Rebuilding Crime Prevention Through Environmental Design: Strengthening the Links with Crime Science (pp. 153-183). Oxan, UK: Routledge. 
Massoomeh Hedayati Marzbali, Aldrin Abdullah \& Mohammad Javad Maghsoodi Tilaki

Surveillability and Guardianship Attitudes: The Role of Multiple Mediators

Marzukhi, M. A., Afiq, M. A., Leh, O. L. H., \& Abdullah, Y. A. (2018). THE DEFENSIBLE SPACE CONCEPT IN NEIGHBOURHOOD PARK CASE STUDY: TAMAN TASIK PUCHONG PERDANA, SELANGOR, MALAYSIA. PLANNING MALAYSIA, 16(7), 274-284.

Mason, P., Kearns, A., \& Livingston, M. (2013). "Safe Going": The influence of crime rates and perceived crime and safety on walking in deprived neighbourhoods. Social Science \& Medicine, 91, 15-24.

Miethe, T. D., \& Meier, R. F. (1990). Opportunity, choice, and criminal victimization: A test of a theoretical model. Journal of Research in Crime and Delinquency, 27(3), 243-266.

Moir, E., Hart, T. C., Reynald, D. M., \& Stewart, A. (2018). Typologies of suburban guardians: understanding the role of responsibility, opportunities, and routine activities in facilitating surveillance. Crime Prevention and Community Safety, $1-21$.

Moley, S. (2008). Public perceptions. In C. Kershaw, S. Nicholas, \& A. Walker (Eds.), The British Crime Survey. London: Home Office Statistical Bulletin.

Newman, O. (1972). Defensible space; crime prevention through urban design New York: Macmillan.

Paquet, C., Cargo, M., Kestens, Y., \& Daniel, M. (2010). Reliability of an instrument for direct observation of urban neighbourhoods. Landscape and Urban Planning, 97(3), 194-201.

Podsakoff, P. M., MacKenzie, S. B., Lee, J. Y., \& Podsakoff, N. P. (2003). Common method biases in behavioral research: a critical review of the literature and recommended remedies. Journal of applied psychology, 88(5), 879-903.

Putnam, R. D. (2007). E pluribus unum: Diversity and community in the twenty-first century the 2006 Johan Skytte Prize Lecture. Scandinavian political studies, $30(2), 137-174$

Reynald, D. M. (2009). Guardianship in action: Developing a new tool for measurement. Crime Prevention \& Community Safety, 11(1), 1-20.

Reynald, D. M. (2010). Guardians on guardianship: Factors affecting the willingness to supervise, the ability to detect potential offenders, and the willingness to intervene. Journal of Research in Crime and Delinquency, 47(3), 358-390.

Reynald, D. M. (2011). Factors Associated with the Guardianship of Places: Assessing the Relative Importance of the Spatio-Physical and Sociodemographic Contexts in Generating Opportunities for Capable Guardianship. Journal of Research in Crime and Delinquency, 48(1), 110-142.

Reynald, D. M. (2018). Guardianship and Informal Social Control. Criminology and Criminal Justice. doi:10.1093/acrefore/9780190264079.013.315

Reynald, D. M., \& Elffers, H. (2009). The Future of Newman's Defensible Space Theory: Linking Defensible Space and the Routine Activities of Place. European Journal of Criminology, 6(1), 25-46.

Reynald, D. M., \& Mihinjac, M. (2019). Using guardianship and Situational Crime Prevention (SCP) to strengthen Crime Prevention Through Environmental Design (CPTED). In R. Armitage \& P. Ekblom (Eds.), Rebuilding Crime Prevention Through Environmental Design: Strengthening the Links with Crime Science (pp. 58-74). Oxan, UK: Routledge. 
Reynald, D. M., \& Moir, E. (2018). Who is watching: exploring individual factors that explain supervision patterns among residential guardians. European Journal on Criminal Policy and Research, 1-20.

Ringle, C. M., Wende, S., \& Becker, J.-M. (2015). SmartPLS 3. Boenningstedt: SmartPLS GmbH, http://www.smartpls.com.

Rukus, J., \& Warner, M. E. (2013). Crime rates and collective efficacy: The role of family friendly planning. Cities, 31, 37-46.

Sampson, R. J., \& Groves, W. B. (1989). Community structure and crime: Testing socialdisorganization theory. American Journal of Sociology, 94(4), 774-802.

Sampson, R. J., Raudenbush, S. W., \& Earls, F. (1997). Neighborhoods and violent crime: A multilevel study of collective efficacy. Science, 277(5328), 918-924.

Shaw, C., \& McKay, H. H. (1942). Juvenile delinquency and urban areas: A study of delinquents in relation to differential characteristics of local communities in American cities: University of Chicago Press.

Shrout, P. E., \& Bolger, N. (2002). Mediation in experimental and nonexperimental studies: new procedures and recommendations. Psychological Methods; Psychological Methods, 7(4), 422-445.

Sohn, D.-W. (2016). Residential crimes and neighbourhood built environment: Assessing the effectiveness of crime prevention through environmental design (CPTED). Cities, 52, 86-93.

Steenbeek, W., \& Hipp, J. R. (2011). A Longitudinal Test of Social Disorganization Theory: Feedback Effects among Cohesion, Social Control, and Disorder. Criminology, 49(3), 833-871.

Stone, C. A., \& Sobel, M. E. (1990). The robustness of estimates of total indirect effects in covariance structure models estimated by maximum. Psychometrika, 55(2), 337-352.

Tewksbury, R., \& Mustaine, E. E. (2003). College students' lifestyles and self-protective behaviors: Further considerations of the guardianship concept in routine activity theory. Criminal Justice and Behavior, 30(3), 302-327.

Wetzels, M., Odekerken-Schröder, G., \& van Oppen, C. (2009). Using PLS path modeling for assessing hierarchical construct models: Guidelines and empirical illustration. Mis Quarterly, 33(1), 177-195.

Wilcox, P., Madensen, T. D., \& Tillyer, M. S. (2007). Guardianship in Context: Implications for Burglary Victimization Risk and Prevention. Criminology, 45(4), 771-803.

Received: January 2020. Accepted: $14^{\text {th }}$ May 2020 